\title{
Analytical Investigation of Seismic Behavior of Building Structures with an Inertial Force-Limiting Floor Anchorage System
}

\author{
D. Zhang, R. B. Fleischman, and Z. Zhang
}

\begin{abstract}
An innovative floor anchorage system is being developed that reduces inertial forces in building structures during major earthquakes. This goal is accomplished by providing the anchorage a design strength lower than that required to transmit the elastic diaphragm forces. Instead, at a predefined "cut-off" load, the anchorage deforms ductily, transforming the diaphragm seismic demands into relative displacement of the floor system with respect to the primary vertical elements of the lateral force resisting system. The floor anchorage system has the potential to reduce the diaphragm inertial forces, thereby lowering floor accelerations and reducing seismic demands on the lateral force resisting system, resulting in less damage to the structure, non-structural elements and building contents. This paper presents preliminary analytical findings on the performance of the floor anchorage system, focusing on the sensitivity of system properties on structural seismic response. The analytical study shows significant seismic response reduction in the proposed floor anchorage system.
\end{abstract}

Index Terms-Seismic resistance system, floor anchorage system, structural damage, structural seismic response.

\section{INTRODUCTION}

In recent years, various types of seismic response reduction systems have been proposed and developed. These systems can be grouped into three broad types [1]: (1) seismic isolation systems; (2) passive energy dissipation systems; and active control systems. Seismic isolation systems [2] decouple the building structure from the damaging components of the earthquake input motion, typically at the foundation [3], but also at upper story levels [4]-[6]. Passive energy dissipation systems mitigate earthquake damage by their capability for enhanced energy dissipation through sliding friction [7], [8], metal yielding [9], [10] or viscoelasticity [11]. Active control system involves active, hybrid and semi-active control methods to modulate structure dynamic properties under earthquake for seismic response reductions [12].

Different than traditional seismic isolation system discussed above to isolate the entire structural or an entire story, an innovative floor anchorage isolation system is being

Manuscript received November 17, 2014; revised February 27, 2015 This work was supported in part by the Network for Earthquake Engineering Simulation (NEES) and National Science Foundation (NSF) under Grant CMMI-1135033, and Nazarbayev University Seeds Grand. The authors are grateful for this support.

D. Zhang is with Nazarbayev University, 53 Kabanbay Batyr Ave, Astana, Republic of Kazakhstan, 010000 (e-mail: dichuan.zhang@nu.edu.kz).

R. B. Fleischman and Z. Zhang are with University of Arizona, 1209 E 2nd Street, Tucson AZ 85721. developed that reduces inertial forces during earthquakes [13]. The system limits inertial forces by possessing a design strength lower than that required to transmit the elastic diaphragm forces. Instead, at this predefined "cut-off" load, the anchorage deforms ductily, transforming the diaphragm seismic demands into relative displacement of the floor system with respect to the primary vertical elements of the lateral force resisting system (LFRS), i.e., shear or core walls, or braced or moment frames. The anchorage system uses this relative motion to dissipate the earthquake energy in the building system. Elastic restoring elements, stabilizing elements and if needed, re-centering elements complete the inertial force-limiting floor anchorage system (abbreviated IFAS in this paper for brevity).

A key aspect of this system is that the isolating effect is introduced between the LFRS and the gravity load resisting system (GLRS), i.e. the floor system and gravity columns. The idea of separating the LFRS and the GLRS is attractive since nearly all of the building's mass originates in the GLRS, in particular within the floor systems, and hence is the source of most of the inertial forces acting during a seismic event.

As a first step in developing the system, relationships between the floor anchorage system yield ("cut-off") strength and the seismic response of structures have to be developed. These relationships are used to establish a design space for the floor anchorage isolation system which is able to reduce the structure seismic demand without excessive relative movement between the floor system and the primary LFRS. This paper presents the preliminary results and findings of an analytical study for developing these relationships for several sensitive parameters of IFAS properties, including strength, stiffness, secondary slope and supplemental damping.

\section{INERTIAL ForCE-LiMITING FLOOR ANCHORAGE SYSTEM} (IFAS)

The basic IFAS concept is to provide a connection system between the LFRS and the GLRS that will partially decouple the systems under seismic excitation in order to lower structural seismic demands (see Fig. 1a). The IFAS is intended to provide an initially stiff connection between the floor diaphragm for normal structural response to daily service wind loading. At a predefined strength, the connection will "cut-off", that is slip or yield, permitting relative movement of the GLRS to the LFRS, thereby partially decoupling the systems. This relative movement will both reduce the transmissibility of accelerations from the LFRS to the floor system, as well as the seismic demands on the LFRS. Through careful choice of a ductile element for the 
primary connector in the IFAS, the relative movement can also be used dissipate the earthquake energy. The IFAS should also possess an elastic restoring characteristic or element for re-centering the floor system. The IFAS has the potential to reduce most response associated with seismic excitation, including demands on the floor diaphragm and the primary vertical LFRS elements (walls, frames, cores) alike as seismic forces carried by building structures originate almost entirely from the inertia of the floor system mass.

The key design parameter of the IFAS is anchorage strength. The parameter $\alpha$ is used in this paper to express the relative strength of the IFAS anchorage to current code diaphragm design forces [14], and is defined as $\alpha=\Sigma F_{y} / F_{p x}$ where $F_{p x}$ is the diaphragm force, $F_{y}$ is the yield strength (predefined cut-off) of the LFRS anchorage system, and the summation occurs for all LFRS anchorages acting in the direction of $F_{p x}$. Note that due to the use of the system overstrength factor $\Omega_{\mathrm{o}}$ and shear strength reduction factor $\phi$ in the design of diaphragm collectors, the point of current code nominal strength is not unity, and instead $\alpha=\Omega_{\mathrm{o}} / \phi$, and thus typically at a value at or near 3.33.

As shown in the Fig. 1b schematic, the $\alpha$ parameter is expected to control or impact the major seismic response parameters of the building structure. As anchorage strength is reduced, the diaphragm and LFRS demands are expected to decrease, while the relative displacement between the floor and LFRS will increase. This tradeoff is a key behavior investigated in this paper. It is important to note that the code value of $\alpha=\Omega_{\mathrm{o}} / \phi$ does not represent an upper bound on system behavior, since diaphragm forces can be significantly higher.

The floor anchorage system is intended to possess the following characteristics: 1) initially stiff and strong to prevent the relative movement between the floor and LFRS under daily wind service level earthquake; 2) sufficient deformation capacity to accommodate the large relative movement; 3) energy dissipation capabilities; 4) partial or full self-centering or post-event re-centering capabilities to minimize the residual relative floor displacement. In addition, the system must possess: 1) sufficient initial stiffness to provide global stability to the gravity system; 2) sufficient bracing of the lateral force resisting system at each floor to provide local (static) stability to the LFRS elements [15].

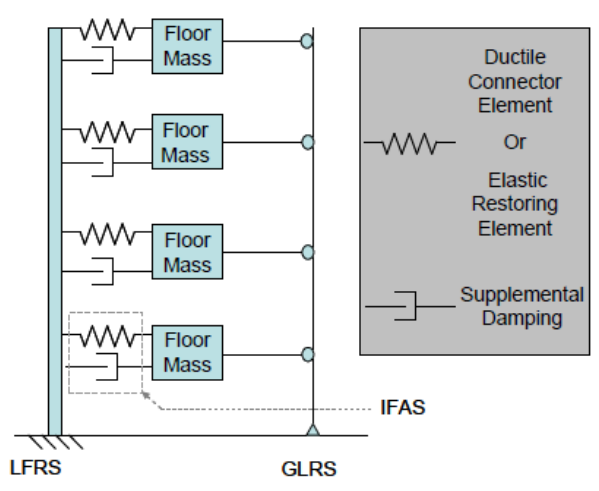

(a)

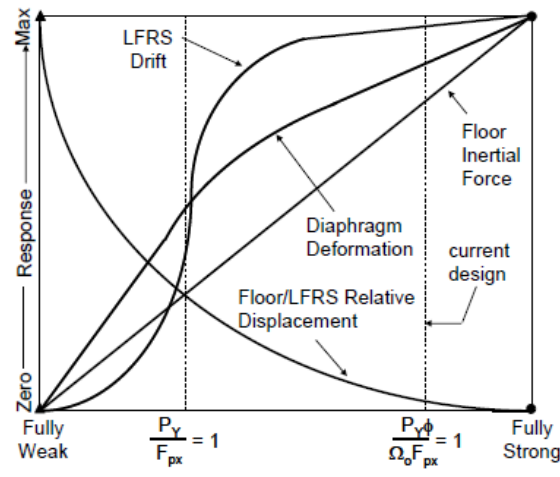

(b)

Fig. 1. IFAS: (a) general concept; (b) anticipated tradeoff in seismic response parameters.

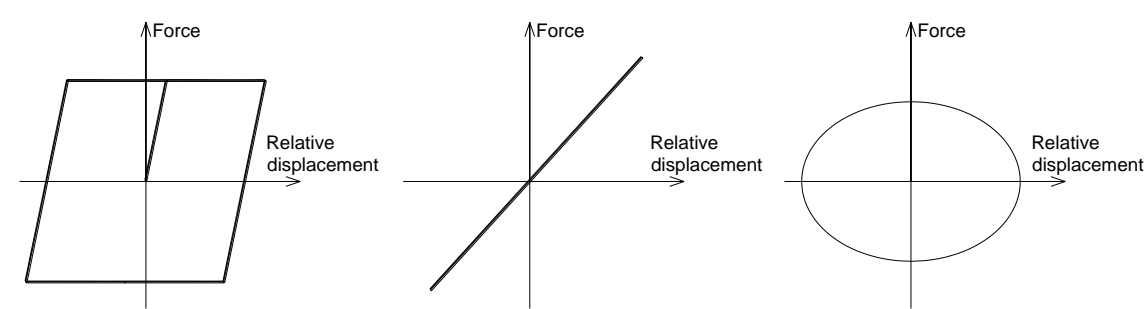

Fig. 2. IFAS elements: (a) hysteretic energy dissipation; (b) elastic restoring; (c) supplemental damping.

Three classes of devices (see Fig. 2) can achieve the required characteristics for the anchorage connector, alone or in combination: 1) hysteretic energy dissipation elements to provide initial stiffness/strength and energy dissipation; 2) elastic restoring elements to provide secondary stiffness and self-centering; and 3) passive damping elements to provide supplemental damping for energy dissipation.

\section{STUDY DESCRIPTION}

The general behavior of building structures employing the IFAS is determined in the study through nonlinear time history analysis (NTHA) of a prototype building structure.

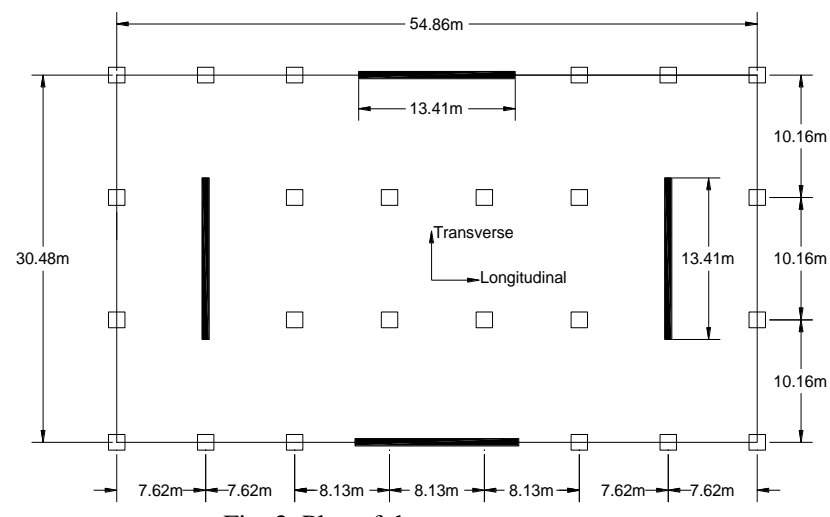

Fig. 3. Plan of the prototype structure. 
The prototype structure is a 12-story reinforced concrete (RC) residential building. As seen in Fig. 3, the structure has a footprint of $54.86 \mathrm{~m} \times 30.48 \mathrm{~m}$ with typical column spacing of $10.16 \mathrm{~m}$ in the transverse direction and approximately $7.62 \mathrm{~m}$ in the longitudinal direction. The LFRS is interior RC shear walls in transverse direction and perimeter RC shear walls in longitudinal direction. The floor slab thickness is $203 \mathrm{~mm}$ resulting in a typical floor mass of $6.46 \mathrm{kPa}$ for normal weight concrete. The floor-to-floor height is $3.2 \mathrm{~m}$ for the typical floor and $4.88 \mathrm{~m}$ at the 1 st story. The seismic design of the prototype structure is based on ASCE 7 [14]. The site is a generic Seismic Design Classification (SDC) D with soil class $D\left(S_{s}=1.5, S_{1}=0.6\right)$. For SDC D, the LFRS is selected as special RC bearing walls $\left(R=5, \Omega_{\mathrm{o}}=2.5, C_{d}=5\right)$.

TABLE I: ANALYTICAL STUDY PARAMETER COMBINATIONS.
\begin{tabular}{|c|c|c|c|c|}
\hline \multirow{2}{*}{ Study Set } & $\alpha$ & $\delta_{y}(\mathrm{~cm})$ & $\beta$ & $\gamma$ \\
\hline 1 & & 0.114 & & \\
2 & & 0.191 & & \\
3 & & 0.254 & 0 & 0 \\
4 & & 0.508 & & \\
5 & & 0.762 & & \\
\cline { 1 - 1 } 6 & $0,0.3,0.5$ & & $0.4 \%$ & \\
7 & $0.75,1.0$, & & $1 \%$ & \\
8 & $1.34,1.68$, & 0.254 & $2 \%$ & 0 \\
9 & $2.35,3.33$, & & $5 \%$ & \\
\cline { 1 - 1 } 10 & & & & $2 \%$ \\
11 & & & & $10 \%$ \\
12 & & 0.254 & $2 \%$ & $20 \%$ \\
13 & & & & $50 \%$ \\
\hline
\end{tabular}

The analytical study parameters in this paper are summarized in Table I. It is noted that this paper focuses on the sensitivity of the structure seismic response to the properties of the floor anchorage system. The primary parameter examined in the analytical study is the floor anchorage strength, as expressed using the normalized anchorage strength $\alpha$. In the study, IFAS designs will possess a constant anchorage strength along the height of the structure. The reference value for current code diaphragm anchorage design strength is $\alpha=\left(\Omega_{\mathrm{o}} F_{p x} / \phi\right) / F_{p x}$, considering both the required application of the system over strength factor to the collector load path [3] most designers interpret the diaphragm anchorage as part of the collector system) and the effect of the strength reduction factor on nominal vs. required strength. The second parameter considered in the study is the floor anchorage initial stiffness $\left(k_{i}\right)$. Given the many strengths levels considered in the study, rather than vary the stiffness value directly, the initial stiffness parameter is varied by assigning a range of yield deformations to the anchorage. Another parameter considered in this study is the secondary slope $\left(k_{2}\right)$ of the floor anchorage system. The secondary slope can be originated from the inherent strain hardening of the ductile connector element or the stiffness of elastic restoring element. In this study, the secondary slop is expressed as the ratio to the initial stiffness $\left(k_{2} / k_{i}\right)$, termed $\beta$.
Finally, the effect of supplemental damping is studied. The supplemental damping, viscous damping here, is added to the floor anchorage system to act as an additional energy dissipation device. The study parameter here for supplemental damping is the damping ratio $\gamma$.

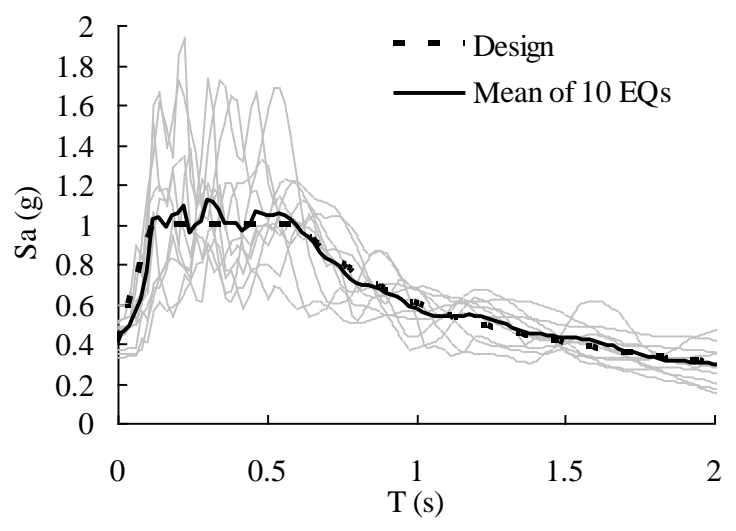

Fig. 4. Response spectrum with 5\% damping.

A suite of 10 ground motions selected from the historical earthquakes is used for the analytical study. The ground motions have been scaled to match the 5\% damping design spectrum for the general (SDC) D site (see Fig. 4) at design basis earthquake (DBE) level. The simulations performed in this paper are at maximum considered earthquake (MCE) level. Therefore the scaled ground motions have been further scaled by a factor of 1.5 for the parametric study. The analytical results presented in this paper are the mean values of the 10 ground motions.

A two-dimensional (2D) models were created using Open Sees for the analytical study as shown in Fig. 5. The intent of evaluating this model is to determine the sensitivity of response to inherent floor anchorage system properties. The LFRS is modeled as elastic beam column element with base hinge (nonlinear rotational spring) representing the behavior of a reinforced concrete shear wall. For the floor anchorage system, the ductile connector and elastic restoring elements are modeled together as a nonlinear spring with a secondary slop and the supplemental damping, if needed, is modeled as a viscous material element with a linear damping model in parallel with the ductile connector.

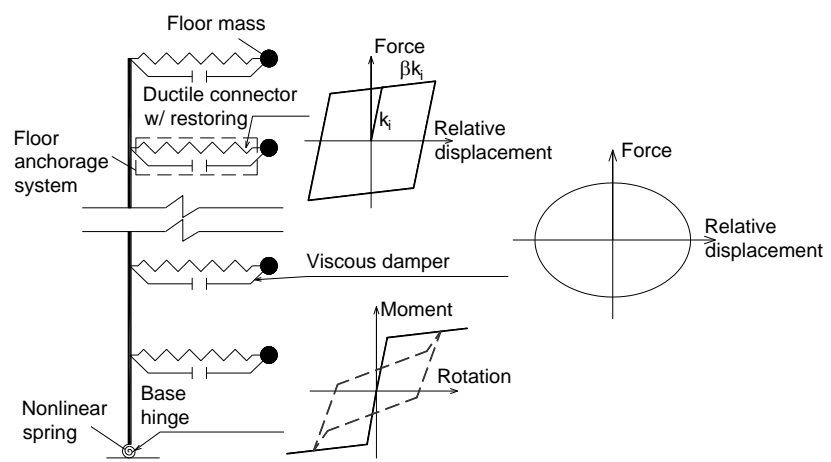

Fig. 5. 2D Model used for the analytical study.

\section{AnAlytical RESUlts}

The sensitivity of IFAS seismic response to the floor anchorage system properties is investigated using mean NTHA results from the full suite of earthquakes. 


\section{A. Effect of IFAS Strength}

Fig. 6 shows the maximum shear wall seismic response vs. the anchorage strength: (a) base flexural plastic rotation; and (b) base shear force normalized by the design shear strength. As seen in Fig. 6, generally shear wall seismic response reduces with the decrease of the anchorage connector strength. However the reductions are different for the flexural and shear response: the shear response reduces immediately by lowering the anchorage strength while the flexural response only starts to reduce until the anchorage strength is lower than $1.0 \mathrm{~F}_{\mathrm{px}}$. This difference is because the shear wall flexural response is controlled by $1^{\text {st }}$ mode response due to base yielding mechanism while the shear wall shear response is directly originated from higher modes driven large floor diaphragm forces (about 8 times of $F_{p x}$ for elastic anchorage). Lowering floor anchorage strength is equivalent as reducing the diaphragm force which therefore can immediately reduce the shear wall shear response but not the flexural response.
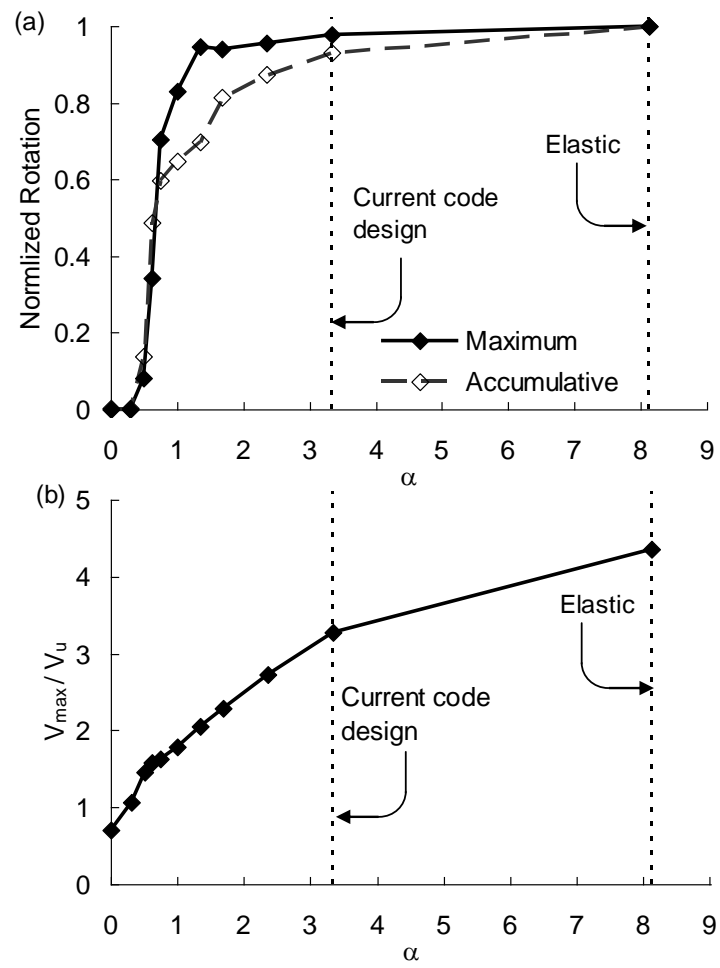

Fig. 6. Shear wall base response: (a) base plastic rotation; (b) base shear force.
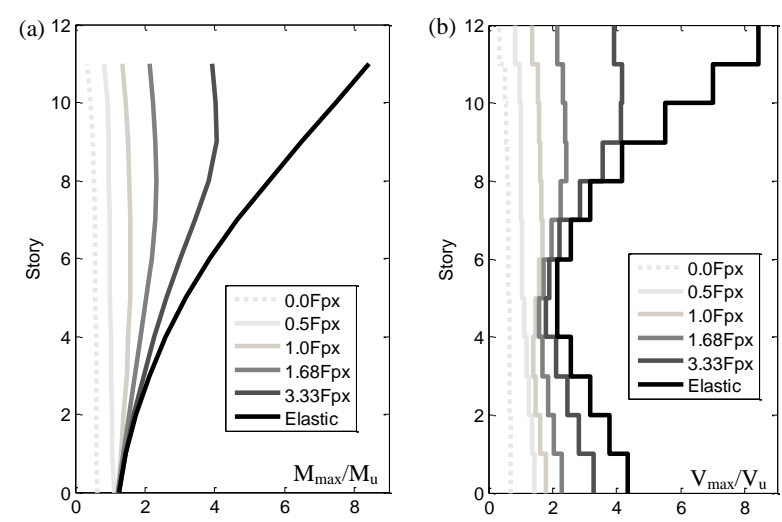

Fig. 7. Shear wall response profile: (a) moment; (b) shear forces.

Fig. 7 shows the maximum response profile along structural height for shear wall moment and shear forces normalized by design moment and shear strength. As seen, both moment (except base moment) and shear forces are reduced immediately as lowering the anchorage strength which indicate that the shear wall flexural response in above stories is also controlled by higher modes driven floor diaphragm forces..

Fig. 8 shows the floor diaphragm acceleration response vs. the anchorage strength: (a) maximum response and (b) response spectrum with $5 \%$ damping created with the acceleration time history at top floor. As seen, because the floor diaphragm acceleration is controlled by the inertia force which can be transferred to the shear wall, it proportionally reduces with the decrease of the anchorage strength, as expected. This reduction in floor diaphragm acceleration indicates two benefits of IFAS to the structural seismic response: 1) reducing the diaphragm forces and reducing the non-structure response.
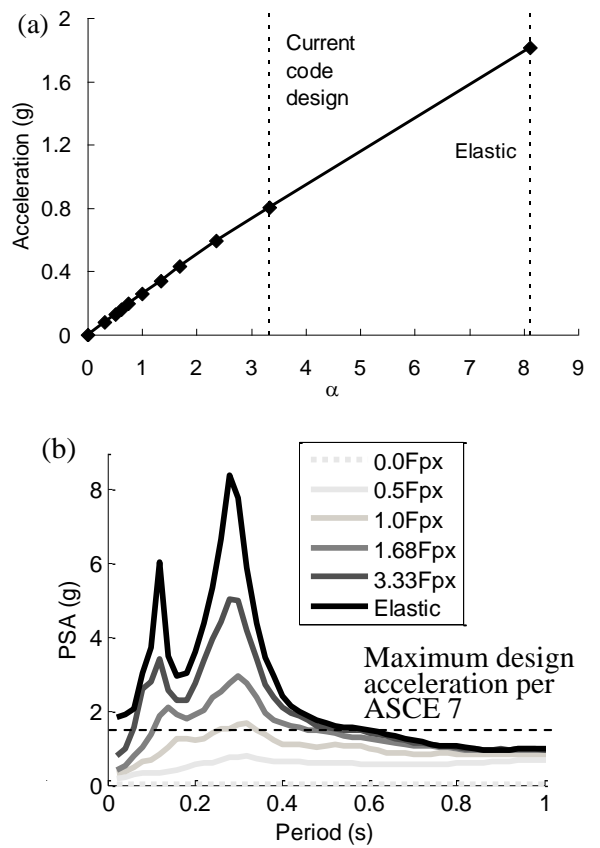

Fig. 8. Diaphragm acceleration: (a) maximum response; (b) response spectrum at top floor.

Second discuss the trade-off response from IFAS. Fig. 9a shows maximum inter-story drift and Fig. 9b shows the maximum relative displacement between the shear wall and floor, i.e. anchorage system deformation. Two trade-off responses are identified here: 1) gravity load resisting system (GLRS) inter-story drift and 2) relative displacement between the shear wall and floor. Both of them increase as reduce of the anchorage system strength. These increases are not significant when the anchorage strength is higher than $1.0 F_{p x}$. However they become more significant as the anchorage strength is lower than $1.0 F_{p x}$ which coincides with significant response reduction of shear wall base rotation (See Fig. 5a). Since benefits and trade-offs of IFAS occur in the same arrange of anchorage strength $(0 \sim 1.0 \mathrm{Fpx})$, it is required to develop design spaces which can reduce the structural response without significant trade-off response. The development of design spaces is discussed in [13]. 

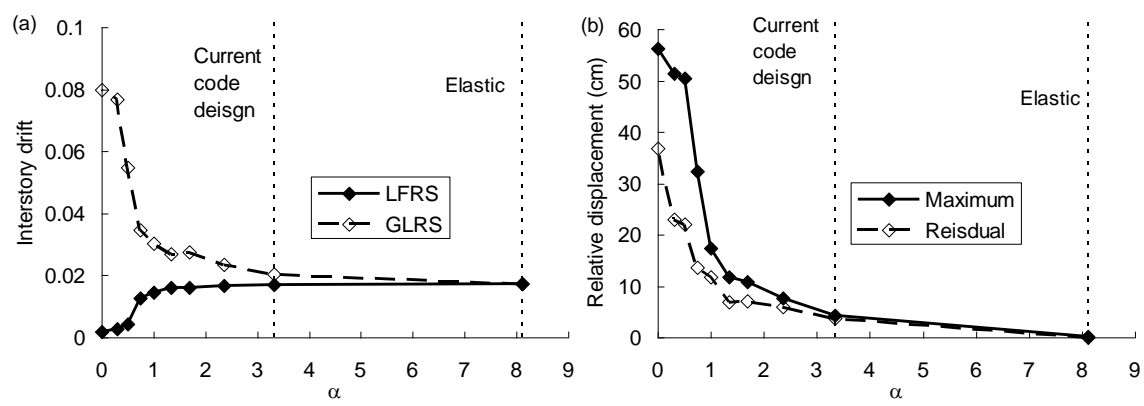

Fig. 9. Trade-off response from IFAS: (a) inter-story drift; (b) relative displacement.
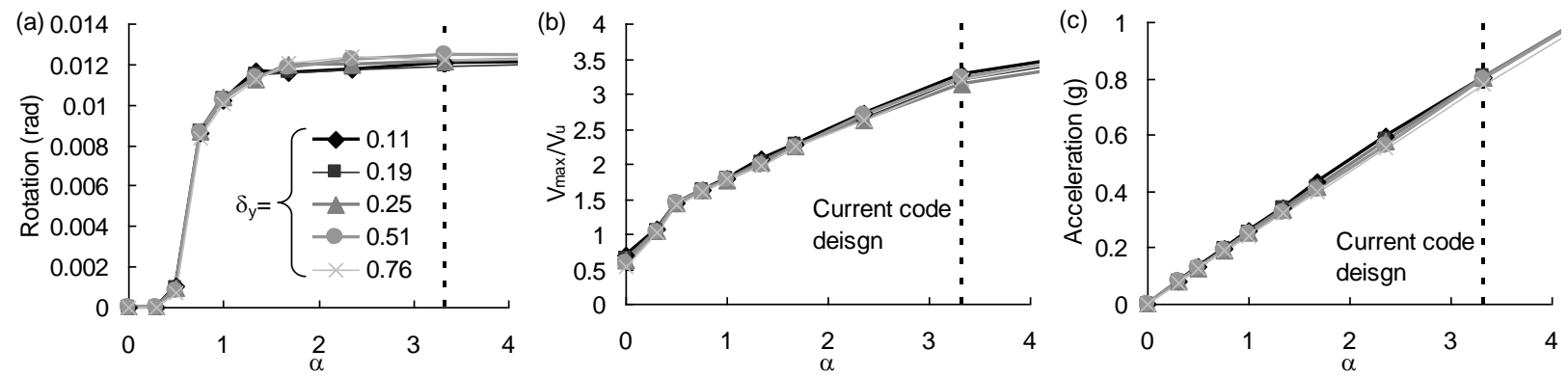

Fig. 10. Structural response for different anchorage initial stiffness: (a) shear wall base rotation; (b) shear wall base shear force; (c) diaphragm acceleration.
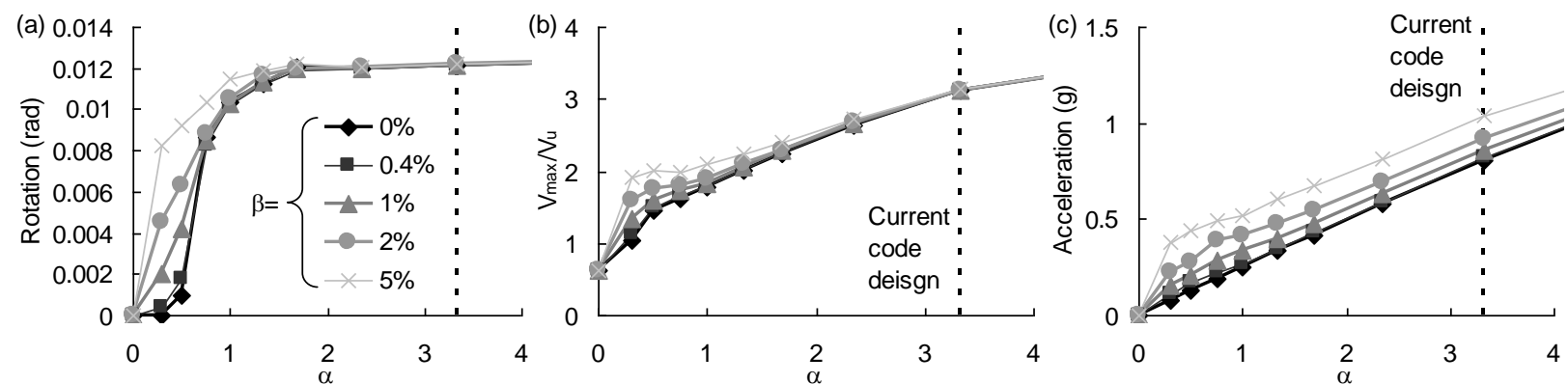

Fig. 11. Structural response for different anchorage secondary slope: (a) shear wall base rotation; (b) shear wall base shear force; (c) diaphragm acceleration
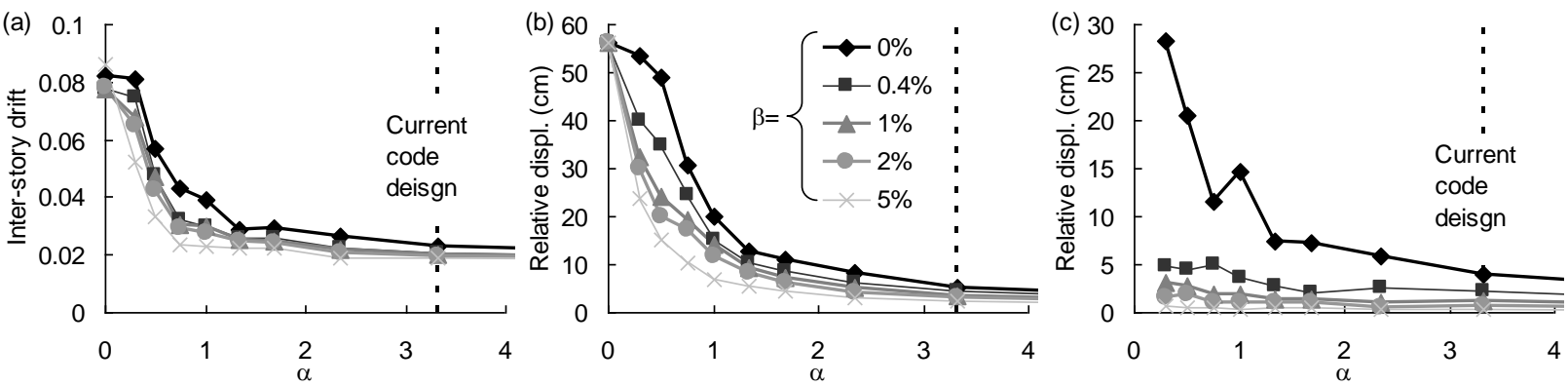

Fig. 12. Trade-off response for different anchorage secondary slope: (a) GLRS; (b) max relative displacement; (c) residual relative displacement.
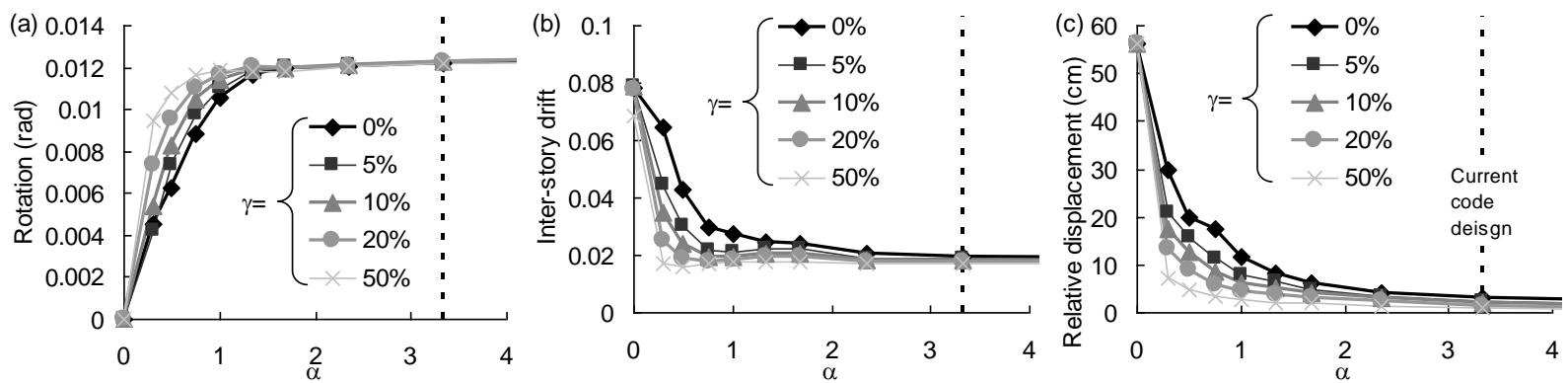

Fig. 13. Structural response for different viscous damping ratio: (a) shear wall base rotation; (b) GLRS drift; (c) max relative displacement.

The above discussed behaviors indicate that IFAS: 1$)$ can reduce higher modes driven response (shear wall shear force, shear wall moment in above stories, diaphragm acceleration and diaphragm force) without increase of the seismic response in the other part of structure; 2 ) can also reduce $1^{\text {st }}$ mode controlled response (shear wall base flexural rotation 
and inter-story drift) but requires increases in the GLRS inter-story drift and the relative displacement between the shear wall and floor.

\section{B. Parameter Sensitivities of Properties of Floor Anchorage System}

Fig. 10 shows the structural response (shear wall base rotation, shear wall base shear force and floor diaphragm acceleration) beneficial from the IFAS for floor anchorage initial stiffness varied from $\delta_{y}=0.11 \mathrm{~cm}$ (rigid) to $\delta_{y}=0.76$ (flexible). As seen, the influence of anchorage initial stiffness on the structural response is very small especially when the anchorage strength is lower than 1.0Fpx.

Fig. 11 shows the structural response (shear wall base rotation, shear wall base shear force and floor diaphragm acceleration) beneficial from the IFAS for floor anchorage secondary slope varied from $\beta=0 \%$ (elastic perfect plastic) to $\beta=5 \%$. As seen, as the secondary slope increases, the speed of the reduction of the structural seismic response with lowering floor anchorage strength deceases due to the strain hardening of the anchorage system.

Fig. 12 shows trade-off response (GLRS inter-story drift, maximum and residual relative displacement between the shear wall and floor) for different floor anchorage secondary slope. As seen in general, the speed of increase of trade-off response reduces as the secondary slope increases. Especially, a small secondary slope significantly reduces the residual relative displacement from $30 \mathrm{~cm}$ to $5 \mathrm{~cm}$ (See Fig. 12c).

Fig. 13 shows the structural response (shear wall base rotation, GLRS drift and floor relative displacement) for supplemental viscous damping varied from $\gamma=0 \%$ (no supplemental damping) to $\gamma=50 \%$. As seen, as the supplemental viscous damping ratio increases, the speed of the reduction of the structural seismic response with lowering floor anchorage strength deceases due to restoring forces provided from the supplement damping element as shown in Fig. 13. However the speed of increase of trade-off response also reduces.

\section{CONCLUSION}

An inertia force-limiting floor anchorage system is being developed through a multi-university NSF/NEES research project. This system is able to reduce inertial forces during major earthquakes and further reduce the seismic demand on the LFRS. This paper presents analytical studies on the general seismic behavior of building structures with the floor anchorage system and the sensitivities of anchorage system properties on the structural seismic response. The following conclusions are made through this study:

1) The structure response, such as LFRS base plastic rotation and shear forces, floor diaphragm accelerations and diaphragm inertia forces under earthquakes can be reduced by lowering the strength of the floor anchorage system. However these reductions come with the increase of the relative displacement between LFRS and GLRS inter-story drift.

2) The 1st mode driven structure response, such as shear wall flexural base plastic rotation and LFRS inter-story drift, can only start to reduce after the floor anchorage strength is lower than $1.0 F_{p x}$. Therefore this reduction typically requires significant relative displacement between LFRS and floor.

3) The higher modes driven structure response, such as shear wall shear forces, shear wall moment in above stories, floor diaphragm accelerations and diaphragm inertia forces, can immediately reduce once the floor anchorage strength starts to reduce from the maximum possible force reached in elastic anchorage system. Therefore this reduction does not require significant relative displacement between LFRS and floor.

4) The stiffness of floor anchorage does not significantly changes the structural seismic response as the strength of floor anchorage does.

5) The secondary slope of the anchorage system significantly reduces the residual relative displacement. It also reduces both benefits and trade-offs response of IFAS.

6) Adding supplemental viscous damping reduces both benefits and trade-offs response of IFAS due to the additional restoring forces from damping forces.

\section{NotATION}

$C_{d}, C_{s}$ : deflection amplification factor, seismic response coefficient;

$F_{p x}:$ diaphragm design force;

$F_{Y}$ : yield strength of the anchorage system;

$k_{i}$ : initial stiffness;

$M_{u}$ : design story moment on LFRS;

$R$ : response modification coefficient;

$S_{1} S_{s}$ : mapped spectral acceleration for 1 second period, short period;

$S_{D S}$ : mapped design spectral acceleration for 1 second period, short period;

$V_{\max }$ : maximum shear forces from analysis;

$V_{u}$ : design story shear on LFRS;

$\alpha$ : strength reduction factor;

$\beta$ : ratio of secondary slope to initial stiffness;

$\delta_{y}$ : yield deformation;

$\gamma$ : viscous damping ratio;

$\phi$ : strength reduction factor;

$\Omega_{0}$ : system overstrength factor.

\section{ACKNOWLEDGMENT}

This research was supported by the Network for Earthquake Engineering Simulation (NEES) and National Science Foundation (NSF) under Grant CMMI-1135033, and by the grant of the Corporate Fund "Fund of Social Development” (№ КФ-14/03) at Nazarbayev University Research and Innovation System. The authors are grateful for this support. Any opinions, findings, and conclusions or recommendations expressed in this material are those of the author(s) and do not necessarily reflect the views of the NEES or National Science Foundation or Nazarbayev University.

\section{REFERENCES}

[1] T. T. Soong and B. F. Spencer, "Supplemental energy dissipation: state-of-the-art and state-of-the-practice," Engineering Structures, vol. 24, pp. 243-259, 2002. 
[2] K. L. Ryan and C. L. Earl, "Analysis and design of inter-story isolation systems with nonlinear devices," Journal of Earthquake Engineering, vol. 14, pp. 1044-1062, 2010.

[3] Z. Fulin, Y. Ping, X. Qiaolin, H. Xiangyun, and Y. Zhen, "Research and application of seismic isolation system for building structures," Journal of Architecture and Civil Engineering, vol. 23, no. 2, pp. 1-8, 2006.

[4] R. Villaverde, M. Aguirre, and C. Hamilton, "Aseismic roof isolation system built with steel oval elements: exploratory study," Earthquake Spectra, vol. 21, no. 1, pp. 225-241, 2005.

[5] R. Villaverde and G. Mosqueda, "Aseismic roof isolation system: analytic and shake table studies," Earthquake Engineering and Structural Dynamics, vol. 28, pp. 217-234, 1999.

[6] Y. Tsuneki, S. Torii, K. Murakami, and T. Sueoka, "Middle-story isolated structural system of high-rise building," in Proc. the 14th World Conference on Earthquake Engineering, Beijing, China, 2008.

[7] I. D. Aiken and J. M. Kelly, "Earthquake simulation testing and analytical studies of two energy-absorbing systems for multistory structures," Earthquake Engineering Research Center at University of California at Berkeley, Report No. UCB/EERC-90/03, 1990.

[8] C. E. Grigorian and E. P. Popov, "Energy dissipation with slotted bolted connections," Earthquake Engineering Research Center at University of California at Berkeley, Report No. UCB/EERC-94/02, 1994.

[9] A. Whittaker, V. Bertero, J. Alonso, and C. Thompson, "Earthquake simulation testing of steel plate added damping and stiffness elements," Earthquake Engineering Research Center at University of California at Berkeley, Report No. UCB/EERC-89/02, 1989.

[10] K. Tsai, H. Chen, C. Hong, and Y. Su, "Design of steel triangular plate energy absorbers for seismic-resistant construction," Earthquake Spectra, vol. 9, no. 3, pp. 505-528, 1993.

[11] M. C. Constantinou and M. D. Symans, "Experimental study of seismic response of buildings with supplemental fluid dampers," The Structural Design of Tall Building, vol. 2, pp. 93-132, 1993.

[12] B. F. Spencer and S. Nagarajaiah, "State of the art of structural control," Journal of Structural Engineering, vol.129, no.7, pp. 845-856, 2003.

[13] D. Zhang, R. Fleischman, J. Restrepo, R. Sause, J. Maffei, D. Mar, and G. Monti, "Development of a floor inertia force limiting anchorage system under earthquake loading," in Proc. the 10th US National Conference on Earthquake Engineering, Earthquake Engineering Research Institute, Anchorage, AK, July 2014.

[14] ASCE/SEI 7, "Minimum design loads for buildings and other structures," ASCE Standard, 2010.

[15] D. Mar and S. Tipping, "Smart frame story isolation system: a new high-performance seismic technology," Internal Report of Tipping Mar Associates, Berkeley, CA, 2000.

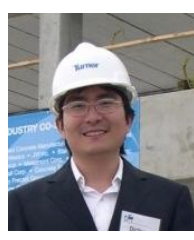

Dichuan Zhang obtained his bachelor in 2002 and he obtained his master degree in civil engineering from Chongqing University, China in 2005. He obtained the $\mathrm{Ph} . \mathrm{D}$. degree in civil engineering from University of Arizona, USA, in 2010

He is now working as an assistant professor in School of Engineering at Nazarbayev University, Kazakhstan.
He has published more than 10 technical papers in academic journals, conferences and reports, has been the reviewer of the US National Science Foundation (NSF) proposals in structural and earthquake engineering and has served as correspondence member in the diaphragm seismic design issue team (IT6) of Building Seismic Safety Council for the next generation of US building seismic design code (ASCE-7 2014). Dr. Zhang's researches have been focused on improving safety and reliability for reinforced concrete structures under extreme loads such as earthquakes and blasts using state-of-art analytical and experimental integrated research methods. He has conducted tons of analytical simulations for building structures using nonlinear dynamic methods and has involved several large scale structural experimental tests including two shake table tests and one advanced hybrid test. Dr. Zhang has been awarded three the US nation awards from Precast/prestressed Concrete Institution.

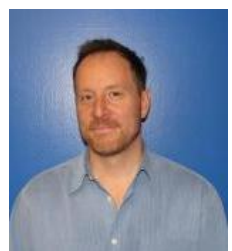

Robert B. Fleischman obtained his bachelor degree in civil engineering from Carnegie Mellon University, USA in 1985. He obtained master in 1989 and Ph.D. degree in civil engineering from Lehigh University, USA in 1995

$\mathrm{He}$ is now working as an associate professor in Department of Civil Engineering and Engineering Mechanics at University of Arizona, USA. His research area is earthquake engineering with a focus on special seismic mitigation systems for buildings, precast/prestressed concrete and steel structures, and progressive collapse of structures due to sudden events, with recent projects involving a $\$ 1.2 \mathrm{M}$ NSF project toward developing a floor anchorage system that protects buildings by reducing the earthquake forces, the use of cast steel components for seismic resistant steel structures, and a $\$ 2.6 \mathrm{M}$ multi-university project toward developing a new design methodology for precast concrete floor diaphragms. The latter work has been included in Part 3 of 2009 National Earthquake Hazards Reduction Program (NEHRP) Recommended Provisions for Seismic Design for New Buildings and has passed the initial ballot for inclusion in the 2014 U.S. Building Codes

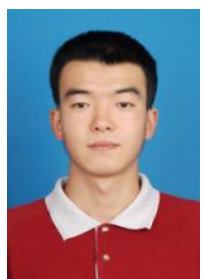

Zhi Zhang obtained his bachelor in civil engineering in 2009 and he obtained his master degree in structural engineering from Southeast University, Nanjing, China. in 2012 .

$\mathrm{He}$ is a Ph.D. Candidate in the University of Arizona, USA. He is now working on a NEESR project: "Inertial Force Limiting Floor Anchorage Systems (IFAS) for Seismic-Resistant Building Structures" from the US National Science Foundation (NSF). He does work on analytical analysis of the building system to evaluate the effect of the proposed system, predict the Shake table test structure response, post-process the shake tabel test data and calibrate the numerical model.

Zhi Zhang did some work on the seisemic performance of the prestressed reinforced concrete frame structure with both shake table test and numerical analysis in his master. Zhi Zhang and his partners also attended two shake table test blind prediction contests (2010 from NEES-EDenfense and 2014 from IEM, China) and were the winners in both of them. 